\title{
Rhinosporidiosis: the largest case series in Brazil
}

\author{
Francílio Araújo Almeida ${ }^{[1],[2], ~ L a i s s o n ~ d e ~ M o u r a ~ F e i t o z a ~}{ }^{[1],[2], ~ J a q u e l i n e ~ D i n i z ~ P i n h o ~}{ }^{[1],[2],}$ \\ George Castro Figueira de Mello ${ }^{[2],[3], ~ J o y c e ~ S a n t o s ~ L a g e s ~}{ }^{[1],[2]}$, Fábio França Silva ${ }^{[1],[2],}$ \\ Raimunda Ribeiro da Silva ${ }^{[2],[4]}$ and Gyl Eanes Barros Silva ${ }^{[2],[4],[5]}$
}

\author{
[1]. Hospital Universitário Presidente Dutra, Universidade Federal do Maranhão, São Luis, Maranhão, Brasil. \\ [2] Rhinosporidiosis Research Group, Hospital Universitário, Universidade Federal do Maranhão, São Luis, Maranhão, Brasil. \\ [3]. Universidade Centro Universitário do Maranhão, São Luis, Maranhão, Brasil. [4]. Departamento de Patologia, Universidade Federal \\ do Maranhão, São Luis, Maranhão, Brasil. [5]. Departamento de Patologia, Faculdade de Medicina de Ribeirão Preto, \\ Universidade de São Paulo, Ribeirão Preto, São Paulo, Brasil.
}

\begin{abstract}
Introduction: Rhinosporidiosis is a chronic infection of the mucous membrane and is caused by Rhinosporidium seeberi, an aquatic mesomycetozoan. The mode of infection is probably transepithelial penetration. The large number of rivers and lakes and the strong presence of riparian populations in the State of Maranhão are strong predisposing factors for rhinosporidiosis. Methods: A 5-year retrospective study was conducted in a tertiary medical center situated in Maranhão, Northeast Brazil. Twenty-five Maranhense patients diagnosed with rhinosporidiosis were analyzed. Results: Most of the patients were children, adolescents and young adults (age range: 7-24 years, mean age: 14 years). The majority of the participants were male (84\%), brown (76\%), and students (92\%). All lesions involved the entire nasal cavity and presented with a vascular polypoid mass. All patients were treated by surgical excision of the lesions. Conclusions: Rhinosporidiosis affects younger age groups, especially students from the countryside and the outskirts of urban areas. This study will aid and guide physicians in diagnosing and treating this infection in endemic areas.
\end{abstract}

Keywords: Rhinosporidiosis. Mesomycetozoea. Nasal obstruction. Endemic disease.

\section{INTRODUCTION}

Rhinosporidiosis has been known for over a 100 years; however, its epidemiology in some countries is poorly characterized. Tropical and subtropical regions are considered endemic areas. The largest number of rhinosporidiosis cases was noted in India and Sri Lanka ( $88 \%$ of total cases), followed by South American and African countries ${ }^{(1)(2)(3)(4)}$. In Europe and the United States, rhinosporidiosis is rarely seen in humans ${ }^{(5)(6)(7)}$.

Rhinosporidiosis is a chronic infection of the mucous membrane that is caused by the mesomycetozoan Rhinosporidium seeber $^{(8)}$. The lesions present as a polypoid or vascular mass, sometimes pedunculated, in the nose $(70 \%)$, eye (15\%), throat, ear, respiratory tract, skin, and even genitalia in both sexes. The most common sites of occurrence include mucosa of the nasal septum, inferior turbinate, and nasal floor ${ }^{(9)(10)(11)}$. The natural habitat of $R$. seeberi is water and the infection probably occurs through transepithelial penetration ${ }^{(4)(8)}$.

Corresponding author: Dr. Gyl Eanes Barros Silva.

e-mail: gyleanes@fmrp.usp.br

Received 24 May 2016

Accepted 21 July 2016
The first case of rhinosporidiosis in Brazil was described in $1933^{(12)}$. However, no detailed study with a considerable number of cases has been reported since then. Therefore, this infection is often overlooked, despite $R$. seeberi being endemic to Brazil. The clinical diagnosis is usually not obvious, and it is even less likely to be diagnosed if a physician is not acquainted with the disease. This results in an overall underdiagnosis of rhinosporidiosis.

The State of Maranhão, located in a tropical region, is the most rural State of Brazil and its geography has a wide diversity of ecosystems. Therefore, the large number of river and lakes and the high presence of riparian populations are strong predisposing factors for rhinosporidiosis. Due to negligence in the diagnosis of rhinosporidiosis and the lack of literature, we propose the need to map this infection in Maranhão and describe the demographical and clinical features of the affected population.

\section{METHODS}

This 5-year retrospective study was conducted at Instituto Maranhense de Oncologia Aldenora Bello, a tertiary medical center situated in Maranhão, Northeast Brazil. We included all patients with a clinically suspicious lesion and standard histopathological confirmation of rhinosporidiosis between 2000 and 2005. We excluded patients who did not return after surgical excision or who had incomplete medical records. 
The following demographic features were described: age, sex, occupation, birthplace, probable location of infection, and current residence. We also reported the following clinical aspects: involvement site, size and number of lesions, presence of bleeding, nasal obstruction, pain, itchiness, lymphadenopathy, involvement of other organs, histopathological report, and treatment.

Quantitative and qualitative variables were collected and tabulated using Microsoft Excel 2013. The data are shown in tables and/or graphs by absolute (n) and relative frequencies (\%). The variable age was categorized by intervals and its mean was calculated.

The study was conducted in accordance with the ethical standards of the local ethical committee, and in keeping with the Helsinki Declaration of 1964, as revised in 1975, 1983, 1989, 1996, and 2000.

\section{RESULTS}

Of the 32 patients examined, 25 met the inclusion criteria. Most of the patients were children, adolescents and young adults (age range: 7-24 years, mean age: 14 years). The majority of the participants were male (84\%), brown $(76 \%)$, and students $(92 \%)$. Most (68\%) of the patients lived in the interior regions of Maranhão State. All patients in São Luis, the state capital, came from the periphery of the city (Figure 1).

All lesions involved the entire nasal cavity and presented with a vascular polypoid mass. In most (64\%) cases, the left nostril was affected, and $2(8 \%)$ cases showed disseminated lesions in the nasopharynx. In 3 cases, the maxillary sinus was involved. The progression of the disease was not mentioned in most medical records, but in 3 cases, this interval ranged from 8 months to 1 year. Demographics, clinical findings, and location of the lesions are represented in Table $\mathbf{1 .}$

All patients presented with nasal obstruction $(80 \%)$, bleeding (68\%), or both. No complaints of pain or itching were noted. Only $3(12 \%)$ cases exhibited a secondary infection. On physical examination, we did not find any enlarged lymph nodes in any of the patients, even in those who had developed an infection (Table 2).

In most cases, the macroscopic aspect of the lesion was rugous, greyish, and friable. The various stages of evolution (spores and juvenile, intermediate, and mature sporangia) of $R$. seeberi was observed histopathologically (Figure 2). The majority of cases involved either respiratory or squamous epithelial lining with evidence of hyperplasia and erosion areas. Other histopathological changes were mucoid degeneration, vascular ectasia, mild fibrosis, and chronic inflammation (sometimes granulomatous). The number of vascular elements (vessels and cords) in the tissue sections was greatly reduced when compared to the amount of fungal elements.

All patients were treated by surgical excision of the lesions. Clinical treatment was restricted to antibiotics and symptomatic agents for cases presenting with secondary infection. Relapse occurred in 2 cases: one case of relapse occurred 3 years after the initial surgical treatment and the other after 8 years. Both relapsed cases presented lesions at the same area. In such cases, the treatment was a new surgical excision with electrocoagulation.

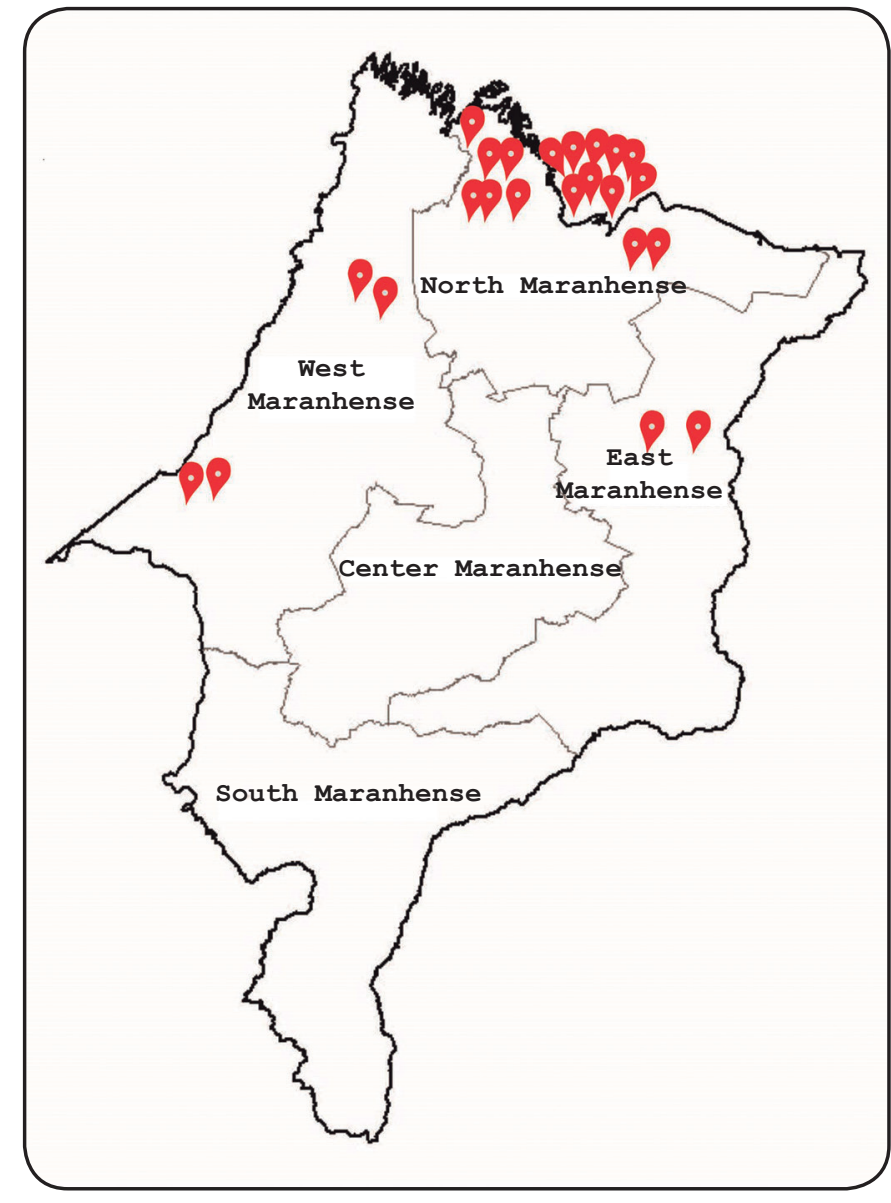

FIGURE 1. Distribution of rhinosporidiosis cases by regions in the State of Maranhão, Brazil.

TABLE 1

Demographic features and location of the lesion in 25 cases of rhinosporidiosis from the State of Maranhão.

\begin{tabular}{lcc}
\hline Variables & Number & Percentage \\
\hline $\begin{array}{l}\text { Sex } \\
\text { male }\end{array}$ & 21 & \\
female & 4 & 16.0 \\
Race & & \\
$\quad$ white & 6 & 24.0 \\
brown & 19 & 76.0 \\
Place of residence & & \\
$\quad$ São Luis & & \\
$\quad$ other cities & 8 & 32.0 \\
Location of the lesion & 17 & 68.0 \\
left nostril & & \\
light nostril & & \\
nasopharynx & 16 & 64.0 \\
\hline
\end{tabular}


TABLE 2

Clinical manifestations of patients with rhinosporidiosis.

\begin{tabular}{lcc}
\hline Findings & Number & Percentage \\
\hline Nasal obstruction & 8 & 32.0 \\
Epistaxis & 5 & 20.0 \\
Obstruction and epistaxis & 12 & 48.0 \\
Secondary infection & 3 & 12.0 \\
\hline
\end{tabular}

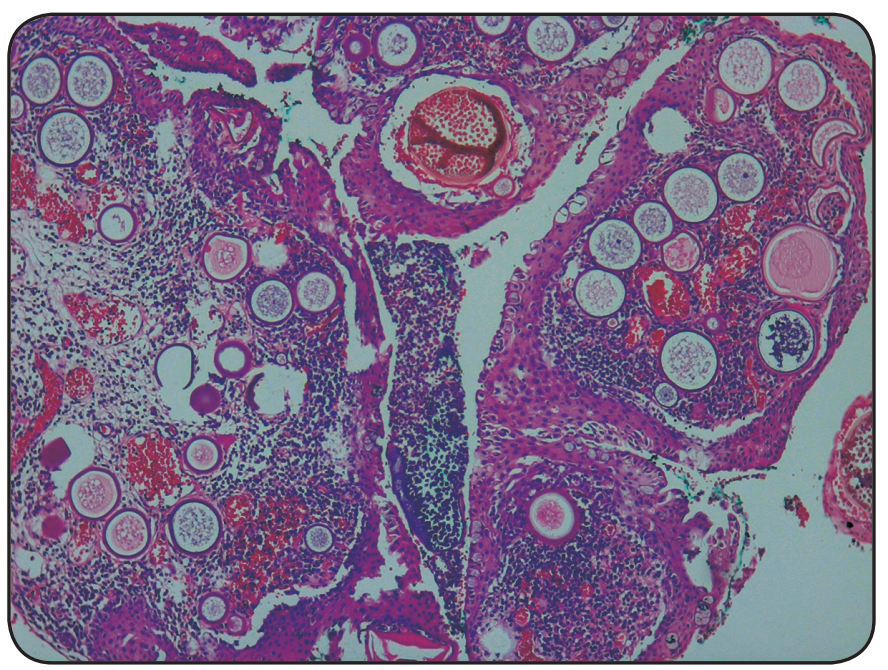

FIGURE 2. Photomicrograph showing numerous sporangia in different phases of maturation with important lymphocyte infiltration.

\section{DISCUSSION}

In this study, patients affected by rhinosporidiosis in Maranhão were found to be younger in age, with a mean age of 14 years, and predominantly male. Similarly, in the literature, males were found to be affected more frequently, especially between the second and fourth decade of life $\mathrm{f}^{(13)(14)(15)(16)}$.

The majority of our patients were from rural areas, suggesting that the pathogenesis of the disease is related to contact with water or soil for transmission ${ }^{(4)}(17)(18)$. In our case, Baixada Maranhense, the marshland area in the State of Maranhão, was the most affected, reinforcing the hypothesis of the relationship between the basins and the local population performing daily activities in ponds, rivers, and lakes.

Although the first case of rhinosporidiosis in Brazil was reported in $1933^{(12)}$, few publications focus on this issue in the country; most papers report isolated cases ${ }^{(19)(20)}$. The two largest case series in Brazil have only $11^{(21)}$ and $10^{(22)}$ cases, and majority patients in both studies were from the State of Maranhão. More recently, a case of cutaneous rhinosporidiosis in a patient from Maranhão has been reported ${ }^{(20)}$; thus, strengthening the endemic nature of the state

In all our patients, the site of infection was the nose. No concomitant infection was observed at other sites (the eye,

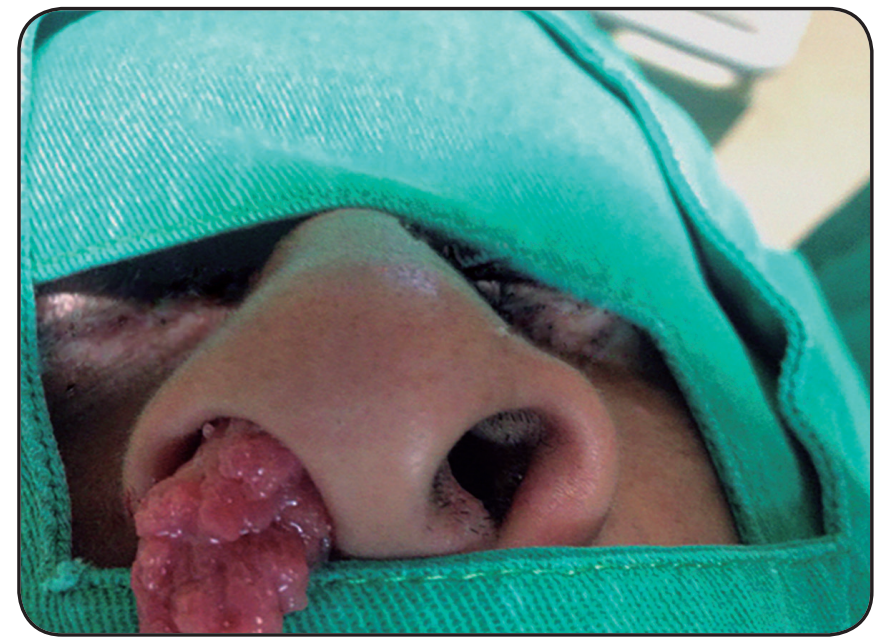

FIGURE 3. Vascular/polypoid mass hanging from the right nostril of a patient with rhinosporidiosis.

lower respiratory tract, vaginal mucosa, skin, or internal organs). This observation is in agreement with the literature, since nasal mucosa is the most commonly area affected globally. A study performed by Sudarshan et al. ${ }^{(15)}$ showed that $81.1 \%$ of cases included nasal and nasopharyngeal involvement. Makannavar and Chavan ${ }^{(16)}$ also reported a similar percentage for nasal involvement $(85 \%)^{(15)(16)}$. Interestingly, in our study, in $64 \%$ cases, infection was found in the left nostril. A review of the relevant literature was performed to assess whether the right or the left nostril is preferentially involved, and no related data were found. The lesions are usually unilateral, single, polypoid, sometimes pedunculated, with typical macroscopic appearance and symptoms (Figure 3$)^{(16)}$. The predominant clinical findings, nasal obstruction, and epistaxis coincide with what is reported in previous studies ${ }^{(11)(18)(23)}$.

Surgical excision was performed in all our patients. In 2 cases, the infection recurred at the same site, indicating a relapse and not a new infection. This could be explained by a failure to cauterize the base of the lesion ${ }^{(16)}$. The ablation technique (cold ablation) may be a promising new tool in the surgical resection of recurrent rhinosporidiosis. This technique reduces the chance of contamination of the surrounding areas and prevents autoinoculation ${ }^{(24)}$. Recently, the antibiotic, dapsone, has shown positive results that complement the treatment, preventing relapses in several infection sites and in cases of inadequate surgical resection ${ }^{(25)(26)(27)}$.

The medicamentous treatment shows limited efficacy probably because the microscopy reveals a large presence of fungal elements when compared with the number of vascular components, and these fungal elements are larger than the phagocytic cells of immune response ${ }^{(25)}$. Furthermore, the impenetrability of the sporangial wall has been implicated for failure of medicamentous treatment and immune response ${ }^{(28)}$.

This study has some limitations such as incomplete medical records, lack of follow-up of some cases, and the low socioeconomic status of the population more vulnerable to 
diseases, which results in low quality of information provided by the patients.

In conclusion, this study reports the largest number of rhinosporidiosis cases in Brazil. This infection affects younger age groups, especially students from the countryside and the outskirts of urban areas. In this study, nasal cavity involvement was present in all patients, and surgical treatment was an effective way to cure the disease. Specifically, in an endemic area like Brazil, any oral or oropharyngeal mass must be considered suspicious for rhinosporidiosis. Because this infection is relatively rare, we hope this study will serve as an aid and guide to the medical community of our country with regard to the diagnosis and treatment of this infection.

\section{Acknowledgments}

We would like to thank Erison Lamar Nunes Junior for his help with the survey research.

\section{Financial support}

This study did not receive any financial support.

\section{REFERENCES}

1. Morelli L, Polce M, Piscioli F, Del Nonno F, Covello R, Brenna A, et al. Human nasal rhinosporidiosis: an Italian case report. Diagn Pathol 2006; 1:25.

2. Echejoh GO, Manasseh AN, Tanko MN, Ogala-Echejoh SE, Silas OA, Nimkur TL, et al. Nasal rhinosporidiosis. J Natl Med Assoc 2008; 100:713-715.

3. Arseculeratne SN, Sumathipala S, Eriyagama NB. Patterns of rhinosporidiosis in Sri Lanka: comparison with international data. Southeast Asian J Trop Med Public Health 2010; 41:175-191.

4. Arseculeratne SN. Recent advances in rhinosporidiosis and Rhinosporidium seeberi. Indian J Med Microbiol 2002; 20:119-131.

5. Sudasinghe T, Rajapakse RP, Perera NA, Kumarasiri PV, Eriyagama NB, Arseculeratne SN. The regional sero-epidemiology of rhinosporidiosis in Sri Lankan humans and animals. Acta Trop 2011; 120:72-81.

6. Leeming G, HetzelU, Campbell T, Kipar A. Equinerhinosporidiosis: an exotic disease in the UK. Vet Rec 2007; 160:552-554.

7. Dadá MS, Ismael M, Neves V, Branco Neves J. Two cases of nasal rhinosporidiosis. Acta Otorrinolaringol Esp 2002; 53:611-614.

8. Sinha A, Phukan JP, Bandyopadhyay G, Sengupta S, Bose K, Mondal RK, et al. Clinicopathological study of rhinosporidiosis with special reference to cytodiagnosis. J Cytol 2012; 29:246-249.

9. Rojas SG, Zumbado SC. Rinosporidiosis. Revista Mèdica de Costa Rica y Centroamerica 2010; 67:399.

10. Abud LN, Pereira JC. Nasal rhinosporidiosis - Four cases relate and literature review. Int Arch Otorhinolaryngol 2007; 11:214-219.
11. Prabhu SM, Irodi A, Khiangte HL, Rupa V, Naina P. Imaging features of rhinosporidiosis on contrast CT. Indian J Radiol Imaging 2013; 23:212-218.

12. Almeida FP de. As blastomycosis no Brasil. An Fac Med São Paulo 1933; 9:69-164.

13. Saha J, Basu AJ, Sen I, Sinha R, Bhandari AK, Mondal S. Atypical presentations of rhinosporidiosis: A clinical dilemma? Indian J Otolaryngol Head Neck Surg 2011; 63:243-246.

14. Ashique KT, Sajid M, Anjit U. Strawberry-shaped lesion on the chest: cutaneous rhinosporidiosis. Indian Dermatol Online J 2014; 5 (suppl 2):S125-S127.

15. Sudarshan V, Goel NK, Gahine R, Krishnani C. Rhinosporidiosis in Raipur, Chhattisgarh: a report of 462 cases. Indian J Pathol Microbiol 2007; 50:718-721.

16. Makannavar JH, Chavan SS. Rhinosporidiosis - a clinicopathological study of 34 cases. Indian J Pathol Microbiol 2001; 44:17-21.

17. Prakash M, Johnny JC. Rhinosporidiosis and the pond. J Pharm Bioallied Sci 2015; 7 (suppl 1):S59-S62.

18. Rath R, Baig SA, Debata T. Rhinosporidiosis presenting as an oropharyngeal mass: a clinical predicament? J Nat Sci Biol Med 2015; 6:241-245.

19. Aquino TA, Costa MC, Costa IM, Campbell IP. Nasal rhinosporidiosis: a report of two cases. Int J Dermatol 2016; doi: 10.1111/ijd.13113. [Epub ahead of print].

20. Vallarelli AF, Rosa SP, Souza EM. Rhinosporidiosis: cutaneous manifestation. An Bras Dermatol 2011; 86:795-796.

21. Silva JF, Silva WM, Nogueira AM, Cavalcante SE. Rinosporidiose nasal - estudo de 11 casos. Rev Soc Bras Med Trop 1975; 9:19-25.

22. Miziara HL, Santos FAM, Kalil RK. Rinosporidiose nasal aspectos epidemiológicos e anatomo-patológicos em 10 casos. Rev Pat Trop 1972; 1:473.

23. Lacaz CS, Porto E, Martins JEC, Heins-Vaccari EM, Melo NT. Rinosporidiose. In: Lacaz CS, Porto E, Martins JEC, HeinsVaccari EM, Melo NT, editors. Tratado de micologia médica Lacaz. $9^{a}$ edição, Sarvier, São Paulo: 2002. p. 755-760.

24. Khan I, Gogia S, Agarwal A, Swaroop A. Recurrent rhinosporidiosis: coblation assisted surgical resection-a novel approach in management. Case Rep Otolaryngol 2014; doi: 10.1155/2014/609784.

25. Madke B, Mahajan S, Kharkar V, Chikhalkar S, Khopkar U. Disseminated cutaneous with nasopharyngeal rhinosporidiosis: light microscopy changes following dapsone therapy. Australas J Dermatol 2011; 52:e4-6. doi: 10.1111/j.1440-0960.2010.00633.

26. Prasad V, Shenoy VS, Rao RA, Kamath PM, Rao KS. Rhinosporidiosis: a chronic tropical disease in lateral pharyngeal wall. J Clin Diagn Res 2015; 9:MD01-2. doi: 10.7860/ JCDR/2015/11831.5951.

27. Pal DK, Mallick AA, Majhi TK, Biswas BK, Chowdhury MK. Rhinosporidiosis in southwest Bengal. Trop Doct 2012; 42: $150-153$.

28. Woodard B, Hudson J. Rhinosporidiosis: ultrasuctural study of an infection in South Carolina. South Med J 1984; 77:1587-1588. 